\title{
Incidência e Severidade de Cancro Cítrico em Laranja 'Pêra Rio' sob Condições de Controle Químico e Proteção com Quebra-Vento
}

\author{
Franklin Behlau ${ }^{1}$, José Belasque Júnior ${ }^{2}$, Armando Bergamin Filho ${ }^{1}$ \& Rui P. Leite Junior ${ }^{3}$
}

${ }^{1}$ Departamento de Entomologia, Fitopatologia e Zoologia Agrícola, ESALQ, Universidade de São Paulo, Cx. Postal 9, CEP 13418-900, Piracicaba, SP, Brasil; ${ }^{2}$ Departamento Científico, Centro de Pesquisas Citrícolas, Fundecitrus, CEP 14807-040, Araraquara, SP, Brasil; ${ }^{3}$ Área de Proteção de Plantas, IAPAR, Cx. Postal 481, CEP 86047-902, Londrina, PR, Brasil, e-mail: ruileitejr@yahoo.com.br

Autor para correspondência: Rui Pereira Leite Junior

BEHLAU, F., BELASQUE JÚNIOR, J., BERGAMIN FILHO, A. \& LEITE JUNIOR, R.P. Incidência e severidade de cancro cítrico em laranja 'Pêra Rio' sob condições de controle químico e proteção com quebra-vento. Fitopatologia Brasileira 32:311-317. 2007.

\section{RESUMO}

Foram estudadas a incidência e severidade de cancro cítrico (Xanthomonas axonopodis pv. citri) em plantas de laranja 'Pêra Rio' (Citrus sinensis) no município de Ourizona, região Noroeste do Estado do Paraná, utilizando controle químico, pela aplicação de bactericida cúprico, e proteção com quebra-vento artificial. Níveis mensais de incidência foram obtidos pela proporção de folhas doentes em relação ao total de folhas avaliadas, enquanto que, níveis mensais de severidade foram determinados por meio de escalas diagramáticas específicas considerando apenas folhas doentes. Os dados foram dispostos em curvas de progresso temporal e analisados com relação à área sob a curva de progresso da doença estandardizada $\left(A U D P C^{*}\right)$ e o coeficiente de determinação $\left(R^{2}\right)$ obtido entre os níveis de incidência e severidade. A aplicação de cobre apresentou efeito significativo na redução dos níveis de cancro cítrico e o emprego de quebra-vento pouco ou nada contribuiu para o controle da doença. Após 29 meses, plantas submetidas à aplicação freqüente de bactericida cúprico apresentaram valores médios de $A U D P C^{*}$ de incidência 43,5\% inferiores aos observados nas plantas não protegidas quimicamente. $\mathrm{O}$ mesmo comportamento foi observado para a severidade da doença. Após 18 avaliações mensais, os valores de $A U D P C^{*}$ de severidade para as plantas submetidas à aplicação de produto cúprico foram $37,1 \%$ menores do que para as plantas não protegidas quimicamente. Para os dois anos agrícolas estudados, os valores de $R^{2}$ entre os níveis de incidência e severidade de cancro cítrico foram superiores a $0,80(\mathrm{p}<0,01)$.

Palavras-chave adicionais: Xanthomonas axonopodis pv. citri, Citrus sinensis, quebra-vento, oxicloreto de cobre.

\begin{abstract}
Citrus canker incidence and severity on 'Pêra Rio' sweet orange under chemical control and windbreak protection

The objective of this work was to study citrus canker incidence and severity under natural conditions in an orchard of ‘Pera Rio' sweet orange planted in Ourizona county, northwest of Parana State, Brazil. Chemical control, by using copper sprays, and windbreak protection were evaluated to reduce citrus canker incidence and severity on leaves. Levels of disease incidence were determined monthly by rating diseased leaves. Severity was evaluated monthly by using specific diagrammatic scales. Levels of severity were calculated considering just the diseased leaves assessed. Data were plotted on temporal progress curves and analyzed regarding the standardized area under disease progress curve (AUDPC*). The coefficient of determination $\left(R^{2}\right)$ between incidence and severity levels was also determined. Whereas copper sprays significantly reduced citrus canker on leaves, windbreak did not contribute significantly to disease control. After 29 assessments, plants submitted to frequent copper sprays showed $A U D P C^{*}$ values for citrus canker incidence $43.5 \%$ lower than those observed on plants not protected with chemical sprays. The same result was observed for citrus canker severity. After 18 assessments, plants sprayed with copper showed $A U D P C^{*}$ values for severity 37.1\% lower than for check plants. In both years, the values of $R^{2}$ between incidence and severity levels were higher than $0.80(\mathrm{p}<0.01)$.
\end{abstract}

Additional keywords: Xanthomonas axonopodis pv. citri, Citrus sinensis, windbreak, copper oxychloride.

\section{INTRODUÇÃO}

O cancro cítrico é uma das mais importantes doenças para a citricultura em diversas regiões do mundo (Gottwald et al., 2002; Stall \& Seymour, 1983). De um modo geral, ocorre de forma severa em regiões de clima quente e úmido no verão, manifestando-se em folhas, frutos e ramos na forma de lesões necróticas, salientes, de coloração marrom, muitas vezes circundadas por halo amarelo quando em folhas e frutos. Os sintomas geralmente são muito característicos, mas podem variar de acordo com o órgão afetado, idade e genótipo do hospedeiro (Bitancourt, 1957; Gottwald et al., 2002; Koizumi, 1985).

Desde a introdução do cancro cítrico no Brasil, em 1957, diversas medidas de controle baseadas nos princípios de “exclusão” e "erradicação" vêm sendo empregadas no intuito de reduzir os danos provocados pela doença (Barbosa et al., 2001; Leite Junior \& Mohan, 1990). Entretanto, os 
esforços adotados na erradicação do patógeno têm sido descontínuos, devido principalmente à resistência dos produtores a essas medidas (Leite Junior, 1990; Santos, 1979). Apesar de apresentar incidência relativamente baixa no Estado de São Paulo, o cancro cítrico se encontra estabelecido endemicamente em algumas regiões do país e sua presença foi recentemente registrada em novas áreas do território nacional e da América do Sul (Barbosa et al., 2001; Braithwaite et al., 2002; Nascimento et al., 2003). Atualmente, apenas o Estado de São Paulo e a Austrália adotam programas de erradicação do cancro cítrico pela eliminação de plantas em áreas infestadas pelo patógeno (Adriaansen, 2005; São Paulo, 1999). Desta forma, torna-se prioritária a avaliação de métodos alternativos de manejo desta doença.

Existem poucos estudos realizados no Brasil relacionados ao comportamento epidemiológico do cancro cítrico sob condições naturais de infecção (Amorim \& Bergamin Filho, 2001; Bergamin Filho et al., 2000; Palazzo et al., 1984). A pequena disponibilidade desse tipo de informação se deve em parte à legislação aplicada em São Paulo. Nesse Estado é obrigatória a adoção de medidas de exclusão e erradicação, incluindo a eliminação de plantas doentes e suspeitas de infecção (São Paulo, 1999). Considerando que invariavelmente estudos epidemiológicos consistentes devem ser realizados em campo, normalmente sob condições naturais de cultivo dos citros e ocorrência da doença, a obtenção de informações referentes à epidemiologia do cancro cítrico e de métodos para seu controle torna-se impraticável quando programas de erradicação da doença pela eliminação de plantas estão sendo implementados. Por outro lado, no Estado do Paraná, as medidas de exclusão e erradicação são menos drásticas, não sendo obrigatória a eliminação de plantas doentes (Leite Junior, 1990; Leite Junior \& Mohan, 1990). Nesse Estado, o manejo integrado da doença envolve basicamente o uso de cultivares resistentes, quebra-ventos e pulverizações com bactericidas cúpricos (Leite Junior \& Mohan, 1990; Leite Junior et al., 1987; McGuire, 1988). Esse tipo de controle tem como base estudos prévios conduzidos no Brasil, antes da introdução da larva minadora (Phyllocnistis citrella), um importante componente do patossistema atual (Gottwald \& Timer, 1995; Leite Junior \& Mohan, 1990; Leite Junior, 1990; Leite Junior et al., 1987)

A introdução da larva minadora dos citros no Brasil, em 1996, tornou o controle do cancro cítrico mais difícil (Bergamin Filho et al., 2000; Gottwald et al., 2005). Os danos provocados pelas fases imaturas do inseto tornam o hospedeiro mais predisposto à infecção pela bactéria, contribuindo para um aumento na freqüência e severidade da doença (Chagas et al., 2001; Graham et al., 1996). Esses fatores resultaram na alteração da dinâmica espacial do cancro cítrico. Padrões de distribuição de plantas doentes passaram a ser menos agregados e focos satélites, distantes dos focos iniciais, passaram a ser encontrados mais facilmente (Bergamin Filho et al., 2000).

Considerando o novo patossistema Citrus -
Xanthomonas axonopodis pv. citri - Phyllocnistis citrella, existente agora no Brasil, em substituição ao anteriormente presente em nossas condições, Citrus - Xanthomonas axonopodis pv. citri, e a necessidade de reavaliação dos métodos de controle, o presente trabalho teve como objetivos avaliar os efeitos da aplicação de bactericida cúprico e proteção com cortina quebra-vento na incidência e severidade do cancro cítrico em pomar com ocorrência endêmica da doença no Estado do Paraná.

\section{MATERIAL E MÉTODOS}

\section{Área experimental}

O presente trabalho foi conduzido no município de Ourizona, região Noroeste do Estado do Paraná com latitude de $23^{\circ} 25^{\prime} \mathrm{S}$, longitude de $52^{\circ} 10^{\prime} \mathrm{W}$ e altitude de $520 \mathrm{~m}$, em pomar de laranja doce do cultivar 'Pêra Rio' [Citrus sinensis (L.) Osbeck], enxertado sobre limão 'Cravo' (Citrus limonia Osbeck) e plantado em espaçamento de $7,0 \mathrm{~m} \times 3,5 \mathrm{~m}$. Segundo a classificação de Köppen, tratase de região com clima subtropical Cfa, caracterizado por apresentar temperatura média no mês mais frio inferior a $18^{\circ} \mathrm{C}$, temperatura média no mês mais quente acima de $22^{\circ} \mathrm{C}$, verões quentes, geadas pouco freqüentes e tendência de concentração das chuvas nos meses de verão, contudo sem estação seca definida. A pluviosidade acumulada do ano para os três meses mais chuvosos, de dezembro a fevereiro, e mais secos, de junho a agosto, varia de 600 a $700 \mathrm{~mm}$ e 225 a $250 \mathrm{~mm}$, respectivamente (Caviglione et al., 2000). O experimento foi iniciado em dezembro de 2002 quando as plantas apresentavam pouco mais de um ano de idade e foi conduzido durante os dois anos subseqüentes, até abril 2005.

\section{Delineamento experimental}

Foi utilizado o delineamento de blocos casualizados com parcelas subdivididas, onde as parcelas representaram a presença ou ausência de cortina quebra-vento, e as subparcelas a aplicação ou não de bactericida cúprico, resultando em quatro tratamentos com três repetições. Cada subparcela compreendeu 32 plantas dispostas em quatro linhas de oito plantas cada. Somente as doze plantas centrais, dispostas em duas linhas de seis plantas cada, foram avaliadas em cada subparcela.

\section{Controle cultural (cortinas quebra-vento)}

Para determinarainfluência dovento sobreaincidência e severidade de cancro cítrico, quebra-ventos artificiais foram instalados visando simular o efeito da proteção normalmente promovida por quebra-ventos arbóreos. Para isso, mourões de eucalipto, com três metros de altura acima do nível do solo, serviram de suporte para tela sombrite com $70 \%$ de retenção, disposta no perímetro das parcelas com cortina quebra-vento. Para evitar a influência da cortina quebravento nas parcelas não protegidas, as parcelas com quebravento foram dispostas respeitando uma distância mínima de cerca de $30 \mathrm{~m}$ das parcelas não protegidas, levando-se em 
consideração a altura da cortina quebra-vento empregada e a distância por ela protegida (Finch, 1988).

\section{Controle químico (bactericida cúprico)}

Foram realizadas pulverizações cúpricas mensais, no período de setembro a abril de cada ano, com o bactericida oxicloreto de cobre (840 g. $\mathrm{kg}^{-1}, 50 \%$ de cobre metálico), na proporção de 180 g do produto comercial para cada $100 \mathrm{~L}$ de calda, utilizando aproximadamente 1,0-1,5 L de calda por planta. As aplicações foram realizadas com pulverizador costal motorizado PL 502500 (Jacto, Pompéia, SP) com capacidade para $13 \mathrm{~L}$ de calda. As subparcelas que não receberam esse tipo de tratamento foram pulverizadas com água.

\section{Avaliações e análise dos dados}

As avaliações de incidência de folhas doentes foram realizadas mensalmente a partir da instalação do experimento em dezembro de 2002 e prosseguiram até abril de 2005. Para determinar a incidência de cancro cítrico em folhas, foram avaliados oito ramos jovens por planta, amostrados em todos os quadrantes da porção mediana das plantas (Leite Junior et al., 1987). A severidade de cancro cítrico foi avaliada mensalmente de novembro de 2003 a abril de 2005. Nessas avaliações foram considerados quatro ramos por planta, amostrados em todos os quadrantes da porção mediana das plantas. Estimativas da severidade foram atribuídas a todas as folhas doentes dos ramos avaliados utilizando escalas diagramáticas (Belasque Júnior et al., 2005). Procurou-se, na medida do possível, avaliar os ramos que pertenciam à última brotação emitida pelas plantas, com idade aproximada de três a seis semanas.

Os dados mensais de incidência e severidade de cancro cítrico foram utilizados na projeção de curvas temporais de progresso da doença. As variáveis estudadas (y) foram plotadas graficamente em função do tempo (x). A partir dessas curvas de progresso, determinou-se a área estandardizada abaixo da curva de progresso da doença estandardizada ( $\left.A U D P C^{*}\right)$ por meio de integração trapezoidal dividida pelo respectivo período de observação, para cada tratamento. Dessa forma, os valores obtidos puderam ser interpretados como a incidência média de cancro cítrico durante a condução do experimento (Campbell \& Madden, 1990; Vale et al., 2004).

Os tratamentos foram comparados por análise de variância e teste de médias. Paralelamente, foi determinado por regressão linear o coeficiente de determinação $\left(R^{2}\right)$ entre os níveis de incidência e severidade de cancro cítrico mensais observados em cada ano estudado. Todas as análises foram feitas empregando o software SAS - Statistical Analysis System (SAS Institute, Cary, CN, EUA).

\section{RESULTADOS}

\section{Incidência de cancro cítrico}

Foi observado o comportamento sazonal da incidência de cancro cítrico em folhas de laranja 'Pêra Rio'. Maiores incidências da doença ocorreram nos meses de temperaturas mais elevadas e precipitações mais freqüentes e intensas (primavera-verão), independentemente da proteção química ou cultural (Figura 1). Esta sazonalidade na incidência de cancro cítrico foi evidente em todos os períodos de condução do experimento, apresentando pico máximo de incidência da doença nos meses de dezembro a fevereiro de cada período. Plantas protegidas quimicamente apresentaram menores incidências de cancro cítrico independentemente da presença de quebra-vento. A proteção promovida pelo controle químico ocorreu durante todo o período avaliado, sendo mais evidente nos meses mais favoráveis à doença (Figura 1). Incidências de cancro cítrico inferiores a 30\% foram observadas a partir de fevereiro de 2004. Em contraste, níveis de $60 \%$ de incidência da doença foram observados em plantas não protegidas pelo bactericida cúprico nos meses de março de 2004 e janeiro de 2005 (Figura 1). A redução da incidência de cancro cítrico, comparando-se plantas de parcelas tratadas e não tratadas quimicamente, foi de aproximadamente $90 \%$ nesse último mês. Plantas submetidas à aplicação freqüente de oxicloreto de cobre apresentaram reduções nos valores médios de $A U D P C^{*}$ superiores a $40 \%$ aos observados nas plantas não protegidas quimicamente (Figura 2). Por outro lado, o quebra-vento, empregado de forma isolada ou combinado com o controle químico, não proporcionou redução significativa na incidência do cancro cítrico (Figura 2).

\section{Severidade de cancro cítrico}

As severidades de cancro cítrico em folhas doentes apresentaram-se relativamente baixas, exceto entre novembro de 2003 e março de 2004 (Figura 3). Neste período foram observados valores médios de 5 a $10 \%$ de severidade em folhas de plantas protegidas ou não pelos tratamentos estudados. Esses valores foram superiores aos observados

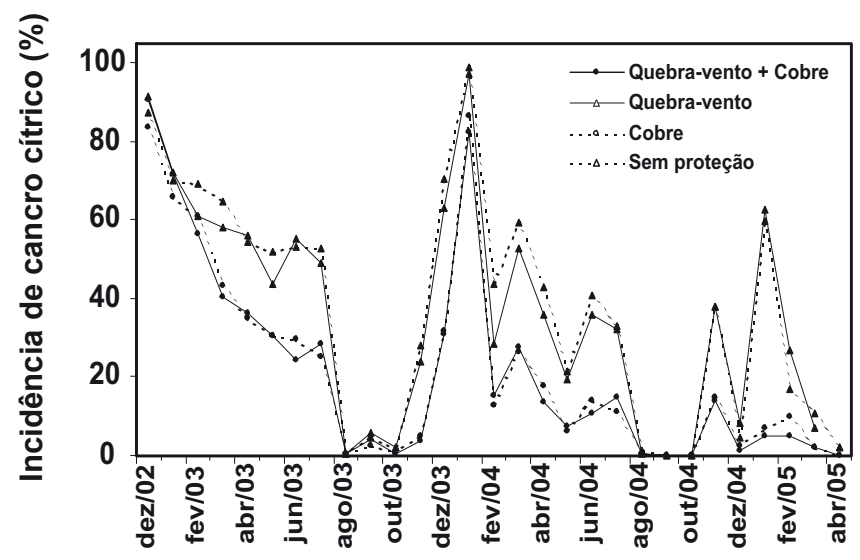

FIG. 1 - Curvas de progresso da incidência de cancro cítrico (Xanthomonas axonopodis pv. citri) em folhas de plantas de laranja ‘Pêra Rio' (Citrus sinensis) protegidas por controle químico (bactericida cúprico) e cultural (quebra-vento), aplicados de forma isolada ou combinada. 


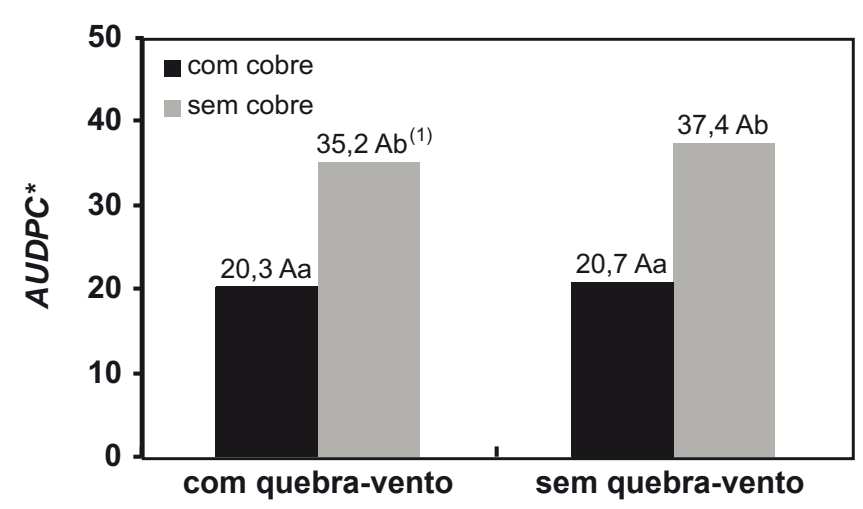

FIG. 2 - Área abaixo da curva de progresso da incidência de cancro cítrico (Xanthomonas axonopodis pv. citri) estandardizada $\left(A U D P C^{*}\right)$, obtida para os níveis de doença observados em folhas de plantas de laranja 'Pêra Rio' (Citrus sinensis) protegidas por controle químico (bactericida cúprico) e cultural (quebra-vento), aplicados de forma isolada ou combinada.

${ }^{(1)}$ Colunas de mesma cor seguidas de letras maiúsculas iguais e colunas de cores diferentes seguidas de letras minúsculas iguais dentro da parcela (presença ou ausência de quebra-vento), não apresentam diferença pelo teste de Tukey ao nível de $5 \%$ de probabilidade. Coeficiente de variação $=4,9 \%$.

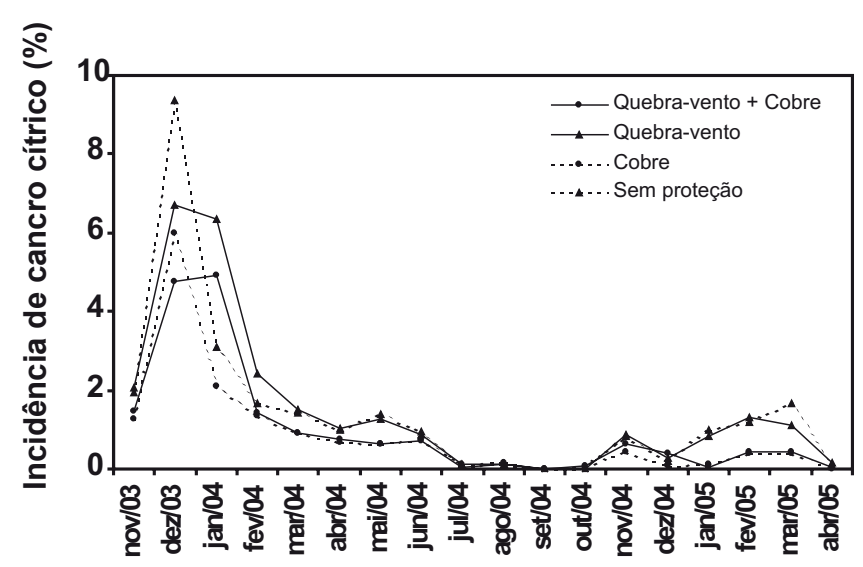

FIG. 3 - Curvas de progresso da severidade de cancro cítrico (Xanthomonas axonopodis pv. citri) em folhas de plantas de laranja 'Pêra Rio' (Citrus sinensis) protegidas por controle químico (bactericida cúprico) e cultural (quebra-vento), aplicados de forma isolada ou combinada.

nos meses subseqüentes, que permaneceram abaixo de 2\% (Figura 3). Os maiores níveis de severidade foram observados no período caracterizado também pelas maiores incidências de folhas doentes (Figura 1). Folhas de plantas submetidas à proteção química apresentaram severidades de cancro cítrico significativamente inferiores às observadas em plantas não tratadas quimicamente, independentemente da proteção com quebra-vento (Figura 4). Considerandose apenas a proteção química, o valor de $A U D P C^{*}$ para severidade de folhas doentes foi de $1,2 \%$, contra $1,9 \%$ para folhas doentes de plantas não tratadas com bactericida cúprico (Figura 4). Esses valores representam uma redução de $37 \%$ na severidade da doença para as plantas submetidas ao controle químico. Da mesma forma como foi observado quanto à incidência de folhas doentes, a proteção com cortina quebra-vento não proporcionou redução significativa da severidade da doença (Figura 4).

\section{DISCUSSÃO}

Tanto os níveis de incidência quanto de severidade refletiram os efeitos promovidos pelos tratamentos avaliados na ocorrência de cancro cítrico. Os coeficientes de determinação $\left(R^{2}\right)$ obtidos entre os níveis de incidência (x) e severidade (y) observados foram iguais a $0,83(y=0,564+$ $0,048 x)$ e $0,86(y=0,036+0,296 x)$ em 2003-2004 e 20042005 , respectivamente $(\mathrm{p}<0,01)$. No entanto, assim como já observado em outros estudos (Gottwald \& Timmer, 1995; McGuire, 1988), as avaliações da incidência de cancro cítrico em folhas refletiram mais acuradamente a flutuação temporal da doença do que as avaliações de severidade. Menores variações ao longo do tempo foram observadas para os dados de severidade, com pequeno reflexo quanto à flutuação nos níveis da doença promovidos por sucessivos ciclos de infecção e emissão de novas brotações e desfolha da planta hospedeira. Empregando-se os dois tipos de avaliação, verificou-se somente o efeito protetor do bactericida cúprico, e não da cortina quebra-vento. No entanto, as diferenças nos valores médios de severidade foram muito menores que as observadas quanto à incidência de folhas doentes. Considerando que uma lesão de cancro cítrico em média abrange cerca de 0,6\% da área foliar (Belasque Júnior et al., 2005), pode-se inferir que, independentemente da utilização de cortina quebra-vento, a aplicação de oxicloreto de cobre promoveu redução na severidade em folhas doentes de aproximadamente uma lesão média da doença por folha.

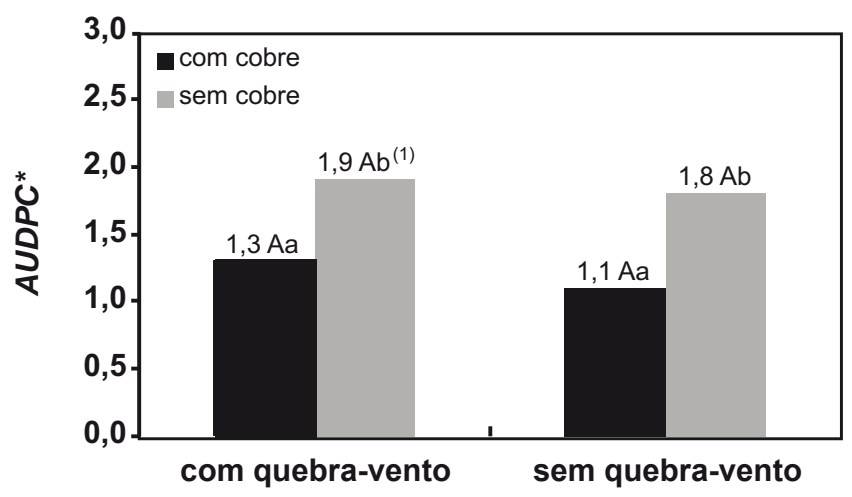

FIG. 4 - Área estandardizada abaixo da curva de progresso da severidade de cancro cítrico (Xanthomonas axonopodis pv. citri) ( $\left.A U D P C^{*}\right)$, em folhas de plantas de laranja 'Pêra Rio' (Citrus sinensis) protegidas por controle químico (bactericida cúprico) e cultural (quebra-vento), aplicados de forma isolada ou combinada

(1) Colunas de mesma cor seguidas de letras maiúsculas iguais e colunas de cores diferentes seguidas de letras minúsculas iguais dentro da parcela (presença ou ausência de quebra-vento), não apresentam diferença pelo teste de Tukey ao nível de $5 \%$ de probabilidade. Coeficiente de variação $=9,6 \%$. 
Isso foi determinado com base na diferença observada entre a severidade em folhas doentes de plantas protegidas quimicamente $(1,2 \%)$ ou não $(1,9 \%)$ (Figura 4). Apesar da pequena diferença em magnitude, esse efeito protetor tem efeito direto na redução de inóculo na planta (Leite Junior et al., 1987; Timmer, 1988).

As incidências de cancro cítrico em folhas apresentaram variações ao longo do tempo, independentemente da medida de controle empregada. As oscilações na incidência da doença estão relacionadas às estações do ano e conseqüentemente às condições climáticas de cada período, tanto em relação ao efeito sobre o hospedeiro, quanto aos efeitos sobre à disseminação do patógeno (Koizumi, 1977; Gottwald et al., 1988). Nos meses de agosto a outubro de 2003 e no mesmo período em 2004, os níveis de incidência da doença foram próximos a zero para todos os tratamentos. Isso se deve provavelmente às menores temperaturas e precipitações do período e pela redução da emissão de fluxos vegetativos pelas plantas. Por outro lado, a doença atingiu níveis máximos sempre nos meses de novembro a fevereiro de cada período, quando a quantidade de tecido suscetível nas plantas foi abundante e as condições climáticas foram mais favoráveis à propagação do patógeno (Leite Junior et al., 1987; Palazzo et al., 1984).

Nas condições do presente estudo, a aplicação de bactericida cúprico apresentou efeito significativo na redução da incidência e severidade de cancro cítrico, enquanto que o uso de cortina quebra-vento pouco ou nada contribuiu no controle da doença. Diversos trabalhos relatam a eficiência da utilização de bactericidas cúpricos no controle químico de cancro cítrico (Gottwald \& Timmer, 1995; Leite Junior \& Moham, 1990; Leite Junior, 1990; Leite Junior et al., 1987; McGuire, 1988; Pereira et al., 1981; Timmer, 1988). Leite Junior et al. (1987) observaram maiores reduções de cancro cítrico empregando-se bactericidas cúpricos em cultivares mais resistentes à doença, com reduções de até 90\% na incidência de folhas doentes. Já em cultivares mais suscetíveis, a redução na incidência da doença foi de até 50\% (Leite Junior et al., 1987).

Apesar da redução da incidência de cancro cítrico em plantas submetidas à proteção de bactericida cúprico ter sido expressiva no segundo ano agrícola estudado, no primeiro período, de agosto 2003 a junho de 2004, essa redução foi menos evidente. No mês de janeiro de 2004, época de maior incidência da doença no primeiro ano agrícola, plantas submetidas a pulverizações cúpricas apresentaram redução de apenas 14\% na incidência de cancro cítrico, em comparação às plantas não tratadas quimicamente. Condições climáticas favoráveis à doença, suscetibilidade do hospedeiro, alta incidência da larva minadora, como observado nas avaliações realizadas (dados não apresentados), e o elevado inóculo inicial, podem ter contribuído para as elevadas incidências em todos os tratamentos estudados e o reduzido efeito protetor desses (Chagas et al., 2001; Leite Junior, 1990; Leite Junior et al., 1987; Gottwald et al, 1988). Por outro lado, a redução da incidência de cancro cítrico no segundo ano, em plantas protegidas quimicamente, pode estar relacionada, entre outros fatores, à redução do inóculo promovida pela proteção química das plantas (Leite Junior et al., 1987; Timmer, 1988). Além do reflexo na incidência e severidade da doença, como observado, o tratamento químico provavelmente reduz também o número de células viáveis presentes nas lesões das plantas submetidas à proteção química. Além disso, a ocorrência de condições climáticas relativamente menos favoráveis à doença (dados não apresentados) e a redução natural dos níveis de cancro cítrico decorrente do desenvolvimento das plantas, assim como observado por Leite Junior (1990), também podem ter contribuído para os menores níveis da doença no segundo período de estudo. É importante ressaltar que a influência desses dois últimos fatores em reduzir os níveis de cancro cítrico foi relativamente menos significativa que a ação do bactericida cúprico, uma vez que em 2005, níveis superiores a $60 \%$ de incidência da doença foram observados para plantas não tratadas quimicamente, independentemente do emprego de quebra-vento.

Considerando que bactericidas cúpricos não possuem efeito sistêmico, esses produtos devem ser pulverizados, necessariamente, enquanto as plantas apresentam-se com tecidos suscetíveis (Gottwald \& Timmer, 1995; Leite Junior, 1990; Leite Junior et al., 1987). Assim, reduções mais significativas na incidência da doença podem ser obtidas com pulverizações em períodos de máxima suscetibilidade, ou seja, logo após a emissão de brotações (Leite Junior, 1990; Leite Junior et al., 1987; McGuire, 1988). No presente estudo, as pulverizações cúpricas foram realizadas mensalmente com intervalos de aproximadamente 28 dias, independentemente da presença de brotações nas plantas. Além disso, ressaltase a presença de plantas não submetidas a qualquer medida de controle da doença, localizadas entre as parcelas experimentais com e sem quebra-vento, as quais podem ter contribuído como fonte de inóculo, como observado por Leite Junior et al. (1987). Por último, pulverizações com maiores volumes de calda que as empregadas no presente estudo, e maiores dosagens de bactericidas cúpricos, podem também resultar em controle mais efetivo da doença (Leite Junior, 1990; Leite Junior et al., 1987).

O uso de cortinas quebra-vento é essencial para o controle de cancro cítrico em áreas que não utilizam a erradicação de plantas como principal medida a ser adotada (Gottwald \& Timmer, 1995; Leite Junior, 1990; Leite Junior et al., 1987). Em estudo conduzido para avaliar o controle químico, aplicado isoladamente ou em conjunto com cortinas de quebra-vento, em condições de campo na Argentina, essa última medida de controle foi a mais efetiva na redução da disseminação da doença (Gottwald \& Timmer, 1995). Comparando-se os estudos conduzidos por esses autores e o aqui apresentado, uma das principais diferenças ocorridas é o fato do referido estudo ter sido iniciado com a inoculação da planta central de cada parcela. Diferentemente, o presente estudo foi iniciado quando a incidência de plantas doentes já tinha atingido $100 \%$. Os dados obtidos não permitem essa 
conclusão, mas postula-se que a ação protetora de cortinas quebra-vento, por reduzir a velocidade do vento incidente, é mais efetiva na disseminação do patógeno entre plantas, com reflexos na incidência de plantas doentes, do que numa mesma planta, o que refletiria na incidência de folhas doentes e na severidade, por exemplo. Além disso, a proteção promovida por uma cortina quebra-vento é influenciada por sua altura efetiva, que é a altura a partir da copa das plantas protegidas (Finch, 1988; Volpe, 1997). No presente caso, já no primeiro ano de condução do experimento, as plantas apresentavamse cerca de um metro e meio abaixo da cortina quebra-vento, altura essa que foi superada ao final do segundo ano. De fato, as reduções máximas observadas da velocidade do vento foram de apenas $20 \%$, tomadas em medições a barlavento e a sotavento na área experimental, ocorridas para ventos com velocidade de até $3 \mathrm{~m} \cdot \mathrm{s}^{-1}$, a velocidade máxima observada no estudo (dados não apresentados).

Com base nas informações apresentadas podese afirmar que tanto as avaliações de incidência como de severidade de cancro cítrico foram eficazes em retratar o comportamento da doença aos diferentes tratamentos estudados. Apenas o controle químico resultou em redução significativa dos níveis da doença. É possível que o uso mais freqüente de bactericida cúprico, em anos subseqüentes, possa aumentar a eficiência dessa medida de controle. Fatores como condições climáticas, genótipo e suscetibilidade do hospedeiro e as inerentes da pulverização do produto, como dosagem, freqüência e tipo de aplicação, entre outros, influenciam fortemente no sucesso do controle.

\section{REFERÊNCIAS BIBLIOGRÁFICAS}

ADRIAANSEN, C. Current status of citrus canker control programs in Queensland, Australia. Proceedings, $2^{\text {nd }}$ International citrus canker and huanglongbing research workshop, Orlando, FL. 2005. p. 90.

AMORIM, L \& BERGAMIN FILHO, A. A epidemiologia do cancro cítrico. Summa Phythopathologica 27:151-156. 2001.

BARBOSA, J.C., GIMENES-FERNANDES, N., MASSARI, C.A. \& AYRES, A.J. Incidência e distribuição de cancro cítrico em pomares comerciais do Estado de São Paulo e sul do Triângulo Mineiro. Summa Phytopathologica 27:30-35. 2001.

BELASQUE JÚNIOR, J., BASSANEZI, R.B., SPÓSITO, M.B., RIBEIRO, L.M., JESUS JUNIOR, W.C. \& AMORIM, L. Escalas diagramáticas para avaliação da severidade do cancro cítrico. Fitopatologia Brasileira 30:387-393. 2005.

BERGAMIN FILHO, A., AMORIM, L., LARANJEIRA, F.F. \& GOTTWALD, T.R. Epidemiology of citrus canker in Brazil with and without the Asian citrus leafminer. Proceedings, International citrus canker research workshop, Fort Pierce, FL. 2000. p. 6.

BITANCOURT, A.A. O cancro cítrico. O Biológico 23:101-111. 1957.

BRAITHWAITE, M., LEITE JUNIOR, R.P., SMITH, J.J., BOA, E. \& SADDLER, G.S. First report of citrus canker caused by
Xanthomonas campestris pv. citri on Citrus sinensis in Bolivia. Plant Pathology 51:383. 2002.

CAMPBELL, C.L. \& MADDEN, L.V. Introduction to plant disease epidemiology. New York. John Wiley \& Sons. 1990.

CAVIGLIONE, J.H., CARAMORI, P.H., KIIHL, L.R.B \& OLIVEIRA, D. Cartas Climáticas do Paraná. Londrina. IAPAR, 2000. CD-ROM.

CHAGAS, M.C.M., PARRA, J.R.P., NAMEKATA, T., HARTUNG, J.S. \& YAMAMOTO, P.T. Phyllocnistis citrella Stainton (Lepidoptera: Gracillariidae) and its relationship with the citrus canker bacterium Xanthomonas axonopodis pv. citri in Brazil. Neotropical Entomology 1:55-59. 2001.

FINCH, S.J. Field windbreaks: design criteria. Agricultural Ecosystems \& Environment 22/23:215-228. 1988.

GOTTWALD, T.R., BASSANEZI, R.B., AMORIM, L. \& BERGAMIN FILHO, A. Spatial pattern analysis of citrus canker infected plantings in Sao Paulo Brazil and implication of the asian leafminer on potential dispersal processes. Proceedings, $2^{\text {nd }}$ International citrus canker and huanglongbing research workshop, Orlando, FL. 2005. p. 17.

GOTTWALD, T.R. \& TIMMER, L.W. The efficacy of windbreaks in reducing the spread of citrus canker caused by Xanthomonas campestris pv. citri. Tropical Agriculture 72:194-201. 1995.

GOTTWALD, T.R., GRAHAM, J.H. \& SCHUBERT, T.S. Citrus canker: the pathogen and its impact. Online. Plant Health Progress. DOI:10.1094/PHP-2002-0812-01-RV. 2002. http://www. plantmanagementnetwork.org/php.

GOTTWALD, T.R., McGUIRE, R.G. \& GRAHAM, S. Asiatic citrus canker: spatial and temporal spread in simulated new planting situations in Argentina. Phytopathology 78:739-745. 1988.

GRAHAM, J.H., GOTTWALD, T.R., BROWNING, H.W. \& ACHOR, D.S. Citrus leafminer exacerbated the outbreak of Asiatic citrus canker in South Florida. Proceedings, International conference on citrus leafminer, Orlando FL. 1996.

KOIZUMI, M. Citrus canker: The world situation. In: Timmer, L.W. (Ed.) Citrus canker: an international perspective. Gainesville FL. University of Florida. Institute of Food and Agricultural Science. 1985. pp. 2-7.

KOIZUMI, M. Factors related to the occurrence of spring canker caused by Xanthomonas citri (Hasse) Dowson. Bulletin of Fruit Tree Research Station 4:115-129. 1977.

LEITE JUNIOR, R.P. \& MOHAN, S.K. Integrated management of the citrus bacterial canker disease caused by Xanthomonas campestris pv.citri in the State of Paraná, Brazil. Crop Protection 9:3-7. 1990.

LEITE JUNIOR, R.P. Cancro cítrico: prevenção e controle no Paraná. Londrina: Fundação Instituto Agronômico do Paraná, 1990. (Circular, 61).

LEITE JUNIOR, R.P., MOHAM, S.K., PEREIRA, A.L.G. \& CAMPACCI, C.A. Controle integrado de cancro cítrico: efeito da resistência genética e da aplicação da bactericidas. Fitopatologia Brasileira 12:257-263. 1987.

McGUIRE, R.G. Evaluation of bactericidal chemicals for control of Xanthomonas on citrus. Plant Disease 72:1016-1020. 1988.

NASCIMENTO, J.F., RODRIGUES NETO, J., ALVES, J.M.A., RÊGO, M.M. \& ARAÚJO, A.E.S. Ocorrência de cancro cítrico no 
Estado de Roraima. Summa Phythopathologica 29:81-82. 2003.

PALAZZO, D.A., MALAVOLTA JUNIOR, V.A. \& NOGUEIRA, E.M.C. Influência de alguns fatores climáticos sobre o índice de infecção de cancro cítrico, causado por Xanthomonas campestris pv. citri, em laranjeira Valência (Citrus sinensis), em Bataguassu, MS. Fitopatologia Brasileira 9:283-290. 1984.

PEREIRA, A.L.G., CAMPACCI, C.A. \& OLIVEIRA, D.A. Cancro Cítrico: seleção e eficiência de defensivos agrícolas em ensaio preliminar de campo. O Biológico 47:235-287. 1981.

SANTOS, C.F.O. O cancro cítrico aos vinte e um anos. Anais, $5^{\circ}$ Congresso Brasileiro de Fruticultura, Pelotas, RS. 1979. pp. 10591067.

SÃO PAULO. Leis, decretos, etc. Portaria da Coordenadoria de Defesa Agropecuária (CDA) nº 17 de 06 de Agosto de 1999.
Diário Oficial, 07 de Agosto de 1999. Seção 1, p.14. Dispõe sobre a erradicação do cancro cítrico.

STALL, R.E. \& SEYMOUR, C.P. Canker, a threat to citrus in the gulf-cost states. Plant Disease 67:581-585. 1983.

TIMMER, L.W. Evaluation of bactericides for control on citrus canker in Argentina. Proceedings of Florida State Horticultural Society 101:6-9. 1988.

VALE, F.X., JESUS JUNIOR, W.C. \& ZAMBOLIM, L. Epidemiologia aplicada ao manejo de doenças de plantas. Belo Horizonte. Editora Perffil. 2004.

VOLPE, C.A. Princípios básicos para a instalação e uso de quebraventos e arborização em propriedades agropecuárias. Anais, $3^{\circ}$ Simpósio sobre ecossistema de pastagens, Jaboticabal, SP. 1997. pp. 112-136.

Recebido 27 Abril 2006 - Aceito 24 Agosto 2007 - FB 6046 